Pivit Septiary Chandral Implementasi Kebijakan Pembangunan Kawasan Teknopolitan dalam Bidang Pendidikan di Kabupaten Pelalawan

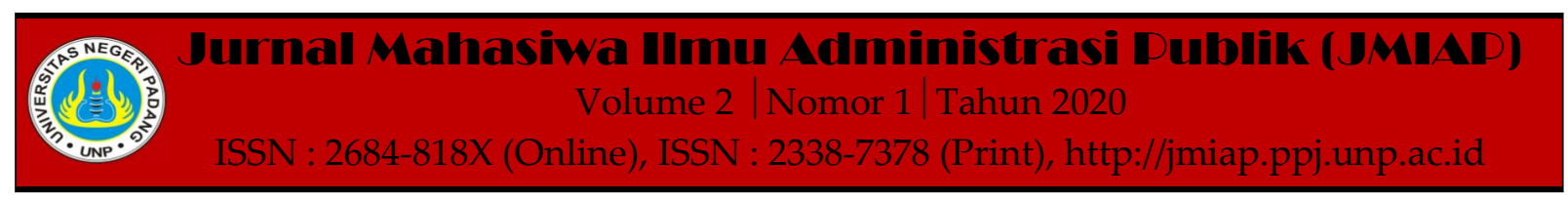

\title{
IMPLEMENTASI KEBIJAKAN PEMBANGUNAN KAWASAN TEKNOPOLITAN DALAM BIDANG PENDIDIKAN DI KABUPATEN PELALAWAN
}

\author{
Pivit Septiary Chandra ${ }^{1(a)}$ \\ ${ }^{1}$ Jurusan Administrasi Negara, Universitas Islam Negeri Sultan Syarif Kasim Riau \\ a)pivit.s.chandra@uin-suska.ac.id
}

\begin{abstract}
This study aims to determine the extent of the Implementation of Development Policy of Technopolitan Regions in the Field of Education in Pelalawan Regency. Informants in this study were the Regent of Pelalawan Regency, Head of Regional Development Planning Agency (BAPPEDA) of Pelalawan Regency, Head of Pelalawan College of Technology and students of the Pelalawan College of Technology. The indicators in this research are the development of Pelalawan College of Technology including facilities, infrastructure, teaching staff, socialization and promotion, research on the development of Pelalawan College of Technology (STTP) have been going quite well. Then, research education subsidies indicator including scholarships for teaching staff and scholarships for students of Pelalawan College of Technology are well distributed. The last indicator is stakeholder participation including the development of techno-political areas and student training by stakeholders is quite good. With the results of the study it can be concluded that the implementation of the policy of the development of technopolitan areas in the field of education in Pelalawan Regency has run well based on research indicators that have been studied.
\end{abstract}

Keywords : Policy Implementation, Technopolitan Region, Technopolitan Pelalawan, Education

Corresponding author. Email.pivit.s.chandra@uin-suska.ac.id

How to cite this article. Chandra, P. Septiary. (2020). Implementasi Kebijakan Pembangunan Kawasan Teknopolitan dalam Bidang Pendidikan di Kabupaten Pelalawan. Jurnal Mahasiwa Ilmu Administrasi Publik (JMIAP) Jurusan Ilmu Administrasi Negara Fakultas Ilmu Sosial Universitas Negeri Padang, Volume 2 (1), Hal. 57-69.

http://jmiap.ppj.unp.ac.id

ISSN : 2684-818X (Online), ISSN : 2338-7378 (Print)

Copyright $\bigcirc 2020$. Published by Pusat Kajian-Pemberdayaan dan Pelayanan Masyarakat (PK-P2M) FIS UNP Padang 


\section{PENDAHULUAN}

Maka dalam hal ini Kabupaten Pelalawan serta Badan Pengkajian dan Penerapan Teknologi (BPPT) pada tahun 2012 melalui Kedeputian Pengkajian Kebijakan Teknologi (PKT) berdasarkan Peraturan Presiden Nomor 32 Tahun 2011 tentang Masterplan Percepatan dan Perluasan Pembangunan Ekonomi Indonesia (MP3EI) 2011-2025 mewadahi pengembangan daerah kawasan Teknopolitan di Indonesia.

Sebagai salah satu bagian dari Provinsi Riau, Kabupaten Pelalawan merupakan wilayah yang sangat sentral bukan hanya lokasi geografis tetapi juga melihat bagaimana posisi dan potensi yang dimilikinya. Kabupaten Pelalawan sendiri menetapkan visi pembangunannya dimulai dengan inovasi. Sesuai dengan semangat yang memang sudah digariskan dalam UU No 17 Tahun 2007 tentang Rencana Pembangunan Jangka Panjang Nasional 2025 yang esensinya pembangunan ekonomi Indonesia akan diarahkan kepada pembangunan berbasis pengetahuan terutama penguatan sistem inovasi.

Teknopolitan adalah konsepsi kawasan berdimensi pembangunan ekonomi, sosial dan budaya yang dilakukan oleh sentra kegiatan iptek, kegiatan produktif, dan gerakan masyarakat dengan mempercepat perkembangan inovasi, difusi dan pembelajaran diantara para pelaku. Teknopolitan yang dikembangkan dalam suatu kawasan di suatu daerah dinamakan sebagai kawasan Teknopolitan. Kawasan Teknopolitan lebih menekankan pada pembangunan berbasis teknologi untuk menghasilkan nilai tambah tinggi serta diharapkan dapat mendorong dan mempercepat perekonomian daerah dengan menyediakan sarana dan prasarana bagi berkembangnya kegiatan iptek, kegiatan produktif, dan gerakan masyarakatuntuk berkolaborasi membangun daerah dengan memanfaatakan potensi unggulan yang dimiliki.

Teknopolitan sejatinya adalah pengembangan sebuah Kawasan Ekonomi
Khusus (KEK). Kawasan Eknomi Khusus (KEK) adalah suatu kawasan yang secara geografis dan jurisdiktif merupakan kawasan dimana perdagangan bebas, termasuk kemudahan dan fasilitas duty free atas impor barang-barang modal dan bahan baku komodiats ekspor, dibuka seluasluasnya (Johansson dan Nilsson dalam Syarif Hidayat dan Agus syarip Hidayat, 2010) Kawasan Teknopolitan Pelalawan merupakan kawasan Teknopolitan yang akan menjadi pembangunan pusat pertumbuhan ekonomi baru yang menjadi kawasan ekonomi khusus di wilayah Kabupaten Pelalawanyang dinilai merupakan suatu keniscayaan dan patut di dukung oleh semua pihak mengingat potensi yang dimiliki serta didukung oleh lokasi wilayah yang strategis dijalur konektivitas koridor ekonomi Sumatra (Masterplan Teknopolitan Pelalawan).

Dalam konteks Masterplan Percepatan dan Perluasan Pembangunan Ekonomi Indonesia (MP3EI), pembangunan Kawasan Teknopolitan dimaksudkan sebagai salah satu bentuk science and technology park berstandar internasional yang menjadi pusat pertumbuhan ekonomi berbasis teknologi untuk meningkatkan nilai tambah potensi sumber daya alam. Pembangunan Kawasan Teknopolitan juga dimaksudkan sebagai wahana kolaborasi terpadu antara pemerintah, lembaga penelitian dan pengembangan, industri, dan masyarakat, untuk mempercepat perkembangan inovasi sebagai kekuatan ekonomi suatu wilayah.

Kabupaten Pelalawan saat ini sedang mengadopsi konsep Teknopolitan untuk membangun wilayahnya. Tetapi pembangunan Teknopolitan ini belum didukung oleh pengembangan sumber daya manusia (SDM), terutama sumber daya manusia (SDM) di sekitar pembangunan kawasan Teknopolitan. Peran pemerintah daerah fase persiapan Kawasan Ekonomi Khusus (KEK) menurut Syarif Hidayat dan Agus Syarip Hidayat (2010) yaitu :

a) Menyiapkan Rencana Tata Ruang Wilayah (RTRW); 
b) Menyiapkan lahan untuk lokasi Kawasan Ekonomi Khusus (KEK);

c) Menyiapkan tenaga kerja;

d) Bersama-sama pemerintah pusat membangun infrastruktur sarana dan prasarana infrastruktur yang diperlukan. Sumber daya manusia dalam pengenbangan kawasan teknopolitan pelalawan ini memegang peranan yang sangat penting sebagai aktor utama dalam pengembangan dan pengelolaan kawasan teknopolitan. Berikut peranan SDM dalam mengembangkan kawasan Teknopolitan (Masterplan Teknopolitan Pelalawan) :

1) Sentra jaringan akademisi, industri dan pemerintahan;

2) Melakukan kegiatan penelitian dan pengembangan yang berorientasi padapenemuan baru, inovasi dan komersialisasi teknologi;

3) Sumber daya manusia mau maju dan bekerja keras untuk membangun Teknopolitan;

4) Memberdayakan masyarakat melalui pendidikaan, pelatihan dan pelibatan dalam pemanfaatan dan pengembangan iptek;

5) Menjadi pusat transfer teknologi kepada masyarakat;
6) Mendorong perkembangan ekonomi dan budaya berbasis pengetahuan dan teknologi.

Berbagai cara dapat ditempuh untuk meningkatkan kompetensi SDM yaitu melalui:

1) Pendidikan dan pelatihan. Pelatihan dapat dilakukan secara internal maupun bekerjasama dengan pihak lain;

2) Pelatihan, Konseling, dan Mentoring;

3) Tolak ukur;

4) Pelatihan pekerjaan;

5) Magang;

6) Delegasi tugas

Dalam upaya menyiapkan sumber daya manusia yang berkualitas bagi kawasan teknopolitan maka pemerintah Kabupaten Pelalawan dalam hal ini membangun sebuah sekolah tinggi di kawasan teknopolitan yang berfokus pada penelitian dan pengenbangan dan sebagai penyedia sumber daya berkualitas yang dibutuhkan untuk mendukung proses pembangunan dan pengelolaan kawasan teknopolitan pelalawan. Berikut tabel jumlah sekolah yang berdasarkan tingkat pendidikan di Kabupaten pelalawan.

Tabel 1. Jumlah Sekolah di Kabupaten Pelalawan

\begin{tabular}{clccc}
\hline No & Tingkat pendidikan & $\mathbf{2 0 1 5}$ & $\mathbf{2 0 1 6}$ & $\mathbf{2 0 1 7}$ \\
\hline 1 & TK/PAUD & 147 & 158 & 158 \\
2 & SD/MI & 226 & 233 & 233 \\
3 & SMP/MTS & 67 & 64 & 64 \\
4 & SMA/SMK/MA & 38 & 40 & 40 \\
5 & PERGURUAN TINGGI & 3 & 3 & 4 \\
\hline
\end{tabular}

Sumber : Badan Pusat Statistik Kabupaten Pelalawan (2017)

Teknopolitan secara langsung atau tidak langsung terkait dengan sektor pendidikan melalui perguruan tinggi sebagai penghasil sumber daya manusia dan intelektual terlatih atau melalui pusat-pusat penelitian pemerintah atau swasta/laboratorium. Baik perguruan tinggi maupun lembaga penelitian dan pengembangan berbagi tujuan bersama seperti menyediakan tempat pelatihan bagi pengusaha dan mendukung teknologi bagi kewirausahaan sesuai dengan kompetensi masing-masing. Bahkan, perguruan tinggi dan lembaga penelitian dan pembangunan (litbang) memainkan peran penting dalam Teknopolitan sebagai penggerak pendidikan, pengetahuan baru dan tenaga kerja terlatih secara terus menerus.

Melihat permasalahan diatas tersebut maka penulis tertarik untuk melakukan 
penelitian dengan judul yaitu "Implementasi Kebijakan Pembangunan Kawasan Teknopolitan dalam Bidang Pendidikan di Kabupaten Pelalawan"

\section{TINJAUAN PUSTAKA}

\section{Kebijakan Publik}

Kebijakan merupakan suatu hasil analisis yang mendalam terhadap berbagai alternatif yang bermuara kepada keputusan tentang alternatif terbaik. Secara konseptual kebijakan publik apat dilihat ari kamus administrasi publik Chandler dan Plano (Harbani Pasalong, 2008) yang mengatakan bahwa kebijakan publik adalah pemanfaatan yang strategis terhadap sumber daya yang ada untuk memecahkan masalah publik atau pemerintah.

Definisi lain mengenai kebijakan publik menurut Carl Friedrich (Agustino Leo, 2008) yang mengatakan kebijakan publik adalah serangkaian tindakan atau kegiatan yang diusulkan oleh seseorang, kelompok, atau pemerintah dalam lingkungan tertentu dimana terdapat hambatan-hambatan dan kemungkinankemungkinan dimana kebijakan tersebut diusulakan agar berguna dalam mengatasinya untuk mencapai tujuan yang dimaksud.

Dalam kaitannya dengan definisidefinisi tersebut diatas maka dapat disimpulkan beebrapa karakteristik utama dari suatu definisi kebijakan publik. Pertama, pada umumnya kebijakan publik perhatiannya ditujukan pada tindakan yang mempunyai maksud atau tujuan tetentu daripada perilaku yang berubah atau acak. Kedua, kebijakan publik pada dasarnya mengandung bagian atau pola kegiatan yang dilakukan oleh pejabat pemerintah daripada keputusan yang terpisah-pisah. ketiga, kebijakan publik merupakan apa yang sesungguhnya dikerjakan oleh pemrinitah. Keempat, kebijakan publik dapat berbentuk positif maupun negatif. Secara positif, kebijakan melibatkan beberapa tindakan pemerintah yang jelas dalam menangani suatu permasalahan. Secara negatif, kebijakan publik dapat melibatkan suatu keputusan pejabat pemerintah untuk tidak melakukan suatu tindakan atau tidak mengerjakan apapun padahal dalam konteks tersebut keterlibatan pemerintah sangat diperlukan. Kelima, kebijakan publik, paling tidak secara positif didasarkan pada hukum dan merupakan tindakan yang berdifat memerintah.

\section{Implementasi}

Menurut kamus besar bahasa Indonesia (KBBI), implementasi adalah pelaksanaan, penerapan. Berikut ini adalah beberapa pendapat para ahli yang dikutip dari dalam buku (Harbani Pasalong, 2008) implementasi kebijakan menurut Bernadine R. Wijaya dan Susilo Supardo adalah proses mentrasnformasikan suatu rancana ke dalam praktik. Hinggis mendefinisikan implementasi sebagai rangkuman dari berbagai kegiatan yang didalamnya sumber daya manusia menggunakan sumber daya lain untuk mencapai tujuan strategis.

Dalam derajat lain Daniel Mazmanian dan Paul Sebatier (Agustino Leo, 2008) mendefinisikan implementasi kebijakan sebagai pelaksanaan keputusan kebijaksanaan dasar, biasanya dalam bentuk undang-undang, namun dapat pula berbentuk perintah-perintah atau keputusan-keputusan eksekutif yang penting atau keputusan badan peradilan. Lazimnya, keputusan tersebut mengidentifikasikan masalah yang ingin diatasi, menyebutkan secara tegas tujuan atau sasaran yang ingin dicapai, dan berbagai cara menstrukturkan atau mengukur proses implementasinya.

Van Meter dan Van Horn (Solichin Abdul Wahab, 2012) merumuskan proses implementasi ini sebagai tindakan-tindakan yang dilakukan baik oleh individuindividu/pejabat-pejabt atau kelompokkelompok pemerintah atau swasta yang diarahkan pada tercapainya tujuan-tujuan yang telah digariskan dalam keputusan kebijaksanaan.

Berdasarkan uraian diatas, jadi implementasi itu merupakan tindakan yang dilakukan oleh pemerintah untuk mencapai tujuan yang telah ditetapkan dalam suatu 
keputusan kebijakan. Akan tetapi pemerintah dalam membuat kebijakan juga harus mengkaji terlebih dahulu apakah kebijakan tersebut dapat memberikan dampak yang buruk atau tidak bagi masyarakat. Hal tersebut bertujuan agar suatu kebijakan tidak bertentangan dengan masyarakat, apalagi sampai merugikan masyarakat.

\section{Pembangunan Kawasan Teknopolitan}

Pengertian pembangunan secara umum pada hakekatnya adalah proses perubahan yang terus menerus untuk menuju keadaan yang lebih baik berdasarkan norma-norma tertentu. Mengenai pengertian pembangunan, para ahli memberikan definisi yang bermacam-macam seperti halnya perencanaan. Istilah pembangunan bisa saja diartikan berbeda oleh satu orang dengan orang lain, daerah yang satu dengan daerah lainnya, Negara satu dengan Negara lain. Namun secara umum ada suatu kesepakatan bahwa pembangunan merupakan proses untuk melakukan perubahan (Riyadi dan Deddy Supriyadi Bratakusumah, 2005).

S.P. Siagian ( 2010) memberikan pengertian tentang pembangunan sebagai "Suatu usaha atau rangkaian usaha pertumbuhan dan perubahan yang berencana dan dilakukan secara sadar oleh suatu bangsa, negara dan pemerintah, menuju modernitas dalam rangka pembinaan bangsa (nation building)".

Dari beberapa definisi tersebut, terdaapt kesamaan ide pokok, yaitu adanya suatu proses. Proses disini berarti suatu usaha yang dilakukan terus menerus.

Kawasan Teknopolitan adalah kawasan yang terdiri atas satu atau lebih kegiatan iptek, kegiatan produktif dan gerakan masyarakat pada wilayah tertentu sebagai sistem pembangunan yang ditunjukkan oleh adanya keterkaitan fungsional dan hierarki keruangan sistem inovasi (BAPPEDA Pelalawan).

Pengertian lain mengenai kawasan Teknopolitan adalah suatu kawasan khusus yang dibangun berdasarkan komitmen memiliki satu atau lebih sentra kegiatan iptek yang mampu mewujudkan keterkaitan antara lembaga pendidikan tinggi, lembaga penelitian dan pengembangan, dan industri yang merupakan wahana penguatan jaringan inovasi dalam kerangka sistem inovasi.

Teknopolitan adalah suatu komunitas terstruktur yang ditujukan untuk pengembangan inovasi. Teknopolitan biasanya membawa bersama-sama ke satu lokasi komponen-komponen yang diperlukan untuk membangun inovasi yaitu akademisi, lembaga riset dan perusahaanperusahaan. Semuanya itu diwujudkan dalam suatu momentum dan visi jangka panjang yang dielaborasikan oleh setiap pimpinan ketiga kelompok tadi. Dari sisi manfaat tidak terukur seperti energi, pengetahuan ilmiah, konsensus sosial dan kewirausahaan sama pentingnya dengan manfaat terukur seperti infrastruktur fisik, fasilitas teknologi, investasi litbang (international association of science park).

Secara operasional Teknopolitan adalah berkelompoknya organisasi riset dan organisasi bisnis dengan ketertarikan yang sama dalam semua aspek yang berkaitan dengan pengembangan ilmiah dari laboratorium ke manufaktur dan komersial. Membangun Zona industri dengan komposisinya didominasi oleh UMKM, kantor, beberapa laboratorium dan unit produksi diletakkan dengan penataan lansekap yang menarik.

Bangunan-bangunan tersebut seringkali ditempatkan suatu lokasi tertetu yang terdiri dari perguruan tinggi negeri dan swasta dan lembaga riset yang mapan. Kawasan tersebut menggambarkan sebagai aktivitas kerjasama teknologi ekonomi tinggi menuju inovasi masa depan. Landasan alamiah proses Teknopolisasi dapat dirangkum sebagai berikut:
a. Teknopolitan esensialnya adalah gambaran untuk kekuatan ekonomi dari abad ke 21; yang mendefinisikan lahan produktif
b. Teknopolitan menyediakan tempat untuk organisasi ekonomi baru. Ia 
memenuhi kebutuhan untuk menginstalasi cara produksi baru dengan menemukan hubungan antara industri inovatif, private/pribadi, research publik, dan pendidikan yang lebih tinggi. Salah satu fungsi essensialnya adalah transfer teknologi;

c. Teknopolitan menawarkan suatu jenis lokasi yang perencanaan, arsitektur, dan kepemimpinannya berkaitan untuk mempromosikan socio-productive order yang baru;

d. Teknopolotan menciptakan polarisasi teritorial dengan lokasi geografis yang lebih besar. Hal tersebut menyebabkan tersedianya interface antara hubungan produktif yang berdasarkan kedekatan, perspektif global yang lebih luas, dan stimulus/dorongan untukpekembangan dinamis.

Teknopolitan dapat juga didefinisikan sebagai komunitas terstruktur atau pusat sumber daya yang diarahkan untuk pengembangan inovasi. Teknopolitan dapat dijadikan sebagai wahana yang sangat berguna untuk pembangunan daerah dan transformasi ekonomi, Teknopolitan biasanya terkonsentrasi di satu lokasi atau wilayah (jaringan Teknopolitan) dimana komponen yang dibutuhkan untuk berinovasi adalah universitas, lembaga penelitian, dan perusahaan. Yang terpenting adalah semua pemangku kepentingan berorientasi pada visi jangka panjang.

Organisasi Teknopolitan dapat dijelaskan secara singkat sebagai merencanakan peningkatan inovasi dengan meminimalkan biaya transaksi yang disebabkan oleh kendala kelembagaan yang seringkali dialami dalam kolaborasi dengan lembaga ekonomi. Teknopolitan selanjutnya memainkan aturan baru yang dinamis dalam pendistribusian tenaga kerja yang berkarakterisasikan organisasi industri kontemporer (lama).

Berdasarkan pengertian tersebut diatas, dapat diuraikan mengenai karakteristik dari Teknopolitan meliputi kegiatan antara lain: a. Sebagai kawasan khusus yang berdemensi pada pembangunan ekonomi berbasis teknologi;

b. Kegiatan penelitian dan pengembangan (lembaga riset);

c. Kegiatan pendidikan (universitas /perguruan tinggi);

d. Kegiatan industri (kawasan industri); dan

e. Kegiatan pendukung lainnya (misalnya dukungan infrastruktur, perumahan, dan dukungan fasilitas lainnya).

\section{METODE PENELITIAN}

Penelitian ini dilakukan di Kabupaten Pelalawan tepatnya di Kecamatan Langgam dimana kawasan Teknopolitan akan di bangun serta instansi-instansi di lingkungan Pemerintahan Kabupaten Pelalawan yang berkaitan dengan Implementasi Kebijakan Pembangunan Kawasan Teknopolitan di Bidang Pendidikan di Kabupaten Pelalawan. Penelitian yang penulis gunakan adalah jenis penelitian kualitatif dengan metode deskriptif, yang mana nantinya akan menggambarkan bagaimana hasil pengamatan dan pemikiran dalam yang berkaitan dengan hasil temuan dilapangan. Penelitian ini untuk menggambarkan bagaimana Implementasi Kebijakan Pembangunan Kawasan Teknopolitan Dalam Bidang Pendidikan Di Kabupaten Pelalawan. Informan penelitan, peneliti memakai teknik purposiv sapling dengan teknik pengambilan sample kay informan.

Peneliti menggunakan data primer dan data sekunder, yakni hasil dari wawancara, observasi ke lapangan dan dokumentasi. Pengujian keabsahan data menggunakan teknik triangulasi sumber, yaitu dengan membandingkan hasil pengamatan dengan hasil wawancara. Dan kemudian dianalisis dengan melalui darireduksi data, penyajian data, sampai penarikan kesimpulan 
HASIL DAN PEMBAHASAN

Implementasi Pembangunan Kawasan Teknopolitan di Kabupaten Pelalawan di Bidang Pendidikan

Kebijakan pembangunan kawasan Teknopolitan di Kabupaten Pelalawan pada dasarnya merupakan bentuk implementasi atau perwujudan upaya percepatan dan perluasan ekonomi sebagaimana diamanatkan didalam Peraturan Presiden Republik Indonesia No. 32 Tahun 2011 tentang Masterplan Percepatan Perluasan Pembangunan Ekonomi Indonesia (MP3EI) 2010-2025.

Berdasarkan Peraturan Bupati No. 32 Tahun 2015 Tentang Pembangunan dan Pengelolaan Kawasan Teknopolitan Pasal 5 menyebutkan bahwa pembangunan kawasan Teknopolitan mempunyai tujuan mewujudkan lingkungan yang kondusif bagi kolaborasi antar komunitas academia, bisnis, dan pemerintah dalam rangka meningkatkan daya saing daerah dan nasional berbasis inovasi dan ilmu pengetahuan (knowledge based economy).

Hal ini sesuai dengan pernyataan yang disampaikan oleh Asisten I Bagian Pemerintahan Bupati Pelalawan Drs. Zulhelmi, M.Si mengenai kawasan Teknopolitan. Berikut hasil kutipan wawancara dengan Asisten I Bagian Pemerintahan Bupati Pelalawan

"Jadi kawasan Teknopolitan ini merupakan kawasan integrasi antara pendidikan, penelitian, dan industri dan pemerintah. Jadi disitu akan dikembangkan dunia pendidikan, mereka melakukan penelitian, dan hasilnya akan implementasikan dalam bentuk industri. Jadi unsur-unsur inilah yang nanti akan terkandung dalam kawasan Teknopolitan" (Wawancara : 20 April 2017).

Berdasarkan wawancara diatas peneliti mendapat gambaran bahwa kawasan Teknopolitan merupakan suatu kawasan yang mewadahi integrasi antara dunia pendidikan dan penelitian, industri, dan pemerintah. Jadi di kawasan Teknopolitan akan berdiri pusat pendidikan sebagai penyedia tenaga ahli, dan hasil dari penelitian akan di wujudkan dalam bentuk industri.

Pelaksanaan Pembangunan Kawasan Teknopolitan Pelalawan di koordinasikan oleh Badan Perencanaan Pembangunan Daerah (BAPPEDA) Kebupaten Pelalawan.

Dalam pembahasan ini akan dijelaskan bagaimana Implementasi Pembangunan Kawasan Teknopolitan Pelalawan di Bidang Pendidikan serta rekomendasi kebijakan dari hasil penelitian langsung, wawancara mendalam terhadap pihak terkait, serta mengacu pada Peraturan Bupati Nomor 32 Tahun 2015 Tentang Pembangunan dan Pengelolaan Kawasan Teknopolitan Pelalawan yang berfokus pada bidang pendidikan.

\section{Pengembangan Sekolah Tinggi Teknologi Pelalawan (STTP)}

Sekolah Tinggi Teknologi Pelalawan (STTP) mulai beroperasi pada tanggal 4 Agustus 2016 dan menerima calon mahasiswa untuk tahun pertama berdasarkan Surat Keputusan Menristekdikti No.189/KPT/I/2016 pada tanggal 13 bulan Mei 2106.

Hal ini sesuai dengan pernyataan yang diberikan oleh Bupati Pelalawan yang di wakilkan oleh Asisten I Bagian Pemerintahan Drs. Zulhelmi, M.Si pada tanggal 20 April 2017 mengenai perkembangan Sekolah Tinggi Teknologi Pelalawan (STTP). Berikut kutipan hasil wawancara dengan Asisten I Bagian Pemerintahan Bupati Pelalawan

"Untuk saat ini kampus utama Sekolah
Tinggi Teknologi Pelalawan (STTP)
sudah dibangun di areal kawasan
Teknopolitan dan pada tahun2016
kemarin sudah dilakukan soft Opening.
Kemudian perkuliahan juga sudah
berjalan dan perkuliahan sementara
dilaksanakan di Seikijang" (Wawancara
:20 April 2017).

"Untuk saat ini kampus utama Sekolah Tinggi Teknologi Pelalawan (STTP) sudah dibangun di areal kawasan Teknopolitan dan pada tahun2016 kemarin sudah dilakukan soft Opening. Kemudian perkuliahan juga sudah berjalan dan perkuliahan sementara :20 April 2017). 
Hal serupa juga disampaikan oleh Kepala Sekolah Tinggi Teknologi Pelalawan (STTP) yang diwakilkan oleh Dr. Salmiyati, M.Pd selaku Wakil ketua. Berikut kutipan dari hasil wawancara dengan Wakil Ketua Sekolah Tinggi Teknologi Pelalawan (STTP)

"Sekolah Tinggi Teknologi Pelalawan (STTP) dimulai dari nol jika dilihat proses perkembangannya cukup baik. Sekolah Tinggi Teknologi Pelalawan (STTP) yang merupakan Perguruan Tinggi berbasis Sains dari beberapa kali pengajuan ke Menristekdikti secara administratif pada tahun 2016 mendapatkan izin. Sekarang kita sudah menerima mahasiswa untuk angkatan pertama ada 34 mahasiswa dari dua program studi, yaitu Teknik Industri dan Agroteknologi keduanya program S1" (Wawancara : 27 April 2017).

Mengenai perkuliahan Sekolah Tinggi Teknologi Pelalawan (STTP) yang dilaksanakan sementara di Seikijang dan belum di pindahkan ke kampus utama yang telah dibangun di areal kawasan Teknopolitan. Hal ini dikarenakan sampai saat ini gedung kampus utama yang berada di kawasan Teknopolitan jaringan listrik belum masuk. Untuk mengatasi hal ini Badan Perencanaan Pembangunan Daerah (BAPPEDA) Kabupaten Pelalawan selaku koordinator kawasan Teknopolitan sudah berkoordinasi dengan BUMD Tuah Sekata agar tahun ini gedung kampus Sekolah Tinggi Teknologi Pelalawan (STTP) yang berada di kawasan Teknopolitan sudah di aliri listrik sehingga perkuliahan bisa difokuskan di kawasan Teknopolilan

\section{Sarana dan Prasarana}

Menurut Peraturan Bupati No. 32 tahun 2015 Pasal 8 (1) disebutkan bahwa pembangunan kawasan Teknopolitan mengacu pada Rencana Induk atau Masterplan yang memuat secara komprehensif pemanfaatan ruang, faktor pendukung, prinsip konsep, pencapaian tujuan, dan tahapan pelaksanaan.
Berdasarkan Peraturan tersebut maka Sekolah Tinggi Teknologi Pelalawan (STTP) sebagai sentra ilmu pengetahuan dan teknologi di kawasan Teknopolitan haruslah mempunyai faktor pendukung untuk pencapaian tujuan termasuk sarana dan prasarana.

Berdasarkan wawancara yang peneliti lakukan dengan Penanggungjawab Kepala UPT Teknopolitan Wildansyah, S.Sos, M.Si mengatakan bahwa untuk saat sekarang ini sarana dan prasarana Sekolah Tinggi Teknologi Pelalawan (STTP) untuk saat sekarang sudah memadai dan mencukupi untuk menunjang perkuliahan. Berikut kutipan dari hasil wawancara dengan Penanggungjawab Kepala UPT Teknopolitan

"Untuk saat ini sarana dan prasarana sudah cukup, karena dalam persyaratan dari Menristekdikti sendiri untuk proses izin STTP kemarin harus lengkap mulai dari ruang Lab sampai ke ruang perkuliahan. Sarana dan prasarana lain juga akan terus kita tingkatkan, namun untuk tahun 2017 ini kita masih berfokus pada gedung kampus yang masih 90\%. Lalu untuk aksesibilitas menuju STTP di kawasan Teknopolitan sudah kita bangun jalan multiyear sepanjang 10 km" (Wawancara : 27 April 2017)

Hal senada juga disampaikan oleh Wakil Ketua Sekolah Tinggi Teknologi Pelalawan (STTP) Drs. Salmiyati, M.Pd yang menyatakan bahwa untuk sarana dan prasarana sudah di penuhi oleh Pemerintah kabupaten pelalawan. Berikut kutipan hasil wawancara dengan Wakil Ketua Sekolah Tinggi Teknologi Pelalawan (STTP)

"Jadi kalau untuk sarana dan prasarana
media pembelajaran sudah dilengkapi
semua oleh Pemerintah Kabupaten
pelalawan, baik wi-fi yang online 24 jam
serta alat-alat praktikum dan kita juga
sudah melaksanakan praktikum sesuai
dengan kurikulum yang ada. Dan untuk
alat-alat labaor yang masih kurang kita
dana sudah ada, tinggal para dosen saja


yang akan mengimplementasikan alat-alat praktikum apa saja yang dibutuhkan" (Wawancara : 27 April 2017)

Akan tetapi setelah peneliti melakukan wawancara dengan beberapa mahasiswa Sekolah Tinggi Teknologi Pelalawan (STTP) mengaku bahwa saat ini untuk fasilitas mesih belum lengkap. Berikut kutipan hasil wawancara dengan Muhammad Faiz

"Kalau untuk fasilitas belum lengkap, namun kalau untuk ruang lab ya disini sudah bisa mendukung untuk praktikum. Peralatan yang kurang disini ya seperti peralatan lab, namun untuk infokus dalam kelas sudah ada" (Wawancara : 27 April 2017)

Berdasarkan hasil wawancara dengan beberapa mahasiswa Sekolah Tinggi Teknologi Pelalawan (STTP) peneliti mendapat gambaran bahwa saat ini fasilitas di Sekolah Tinggi Teknologi Pelalawan (STTP) sudah cukup untuk mendukung kegiatan perkuliahan seperti ruang kelas, ruang lab, infokus, $w i-f i$ dan lain-lain. Untuk saat ini hanya alat-alat praktikum yang masih belum lengkap namun hal ini dikarenakan proses perpindahan seluruh kegiatan perkuliahan ke kampus utama yang berada di kawasan Teknopolitan

\section{Tenaga Pengajar}

Sekolah Tinggi Teknologi Pelalawan (STTP) memegang peranan penting dalam pengembangan pembangunan kawasan Teknopolitan Pelalawan. Selain sebagai senta ilmu pengetahuan dan teknologi (iptek), Sekolah Tinggi Teknologi Pelalawan juga berperan sebagai penyedia tenaga kerja terampil yang dibutuhkan kawasan Tekopolitan.

Oleh karena itu Sekolah Tinggi Teknologi Pelalawan (STTP) harus dudukung oleh tenaga pengajar yang professional dan kompeten dibidangnya. Saat ini Sekolah Tinggi Teknologi Pelalawan menyelenggarakan dua program studi jenjang Strata I (SI) yaitu Teknik Industri dan Agroteknologi.

Terkait tenga pengajar di Sekolah Tinggi Teknologi Pelalawan (STTP) berdasarkan hasil wawancara yang peneliti lakukan dengan Asisten I Bagian Pemerintahan Bupati Pelalawan mengatakan bahwa untuk tenaga pengajar di Sekolah Tinggi Teknologi Pelalawan (STTP) Pemerintah Kabupaten Pelalawan telah menyiapkan jauh-jauh hari. Berikut kutipan hasil wawancara dengan Asisten I Bagian Pemerintahan Bupati Pelalawan

"Untuk tengaga pengajar memang kita sudah siapkan jauh-jauh hari. Disini kita bekerja sama dengan Universiti Teknologi Malaysia (UTM). kita melakukan rekrutmen melalui online di website resmi Kabupaten Pelalawan. Jadi para dosen yang melamar kami seleksi lagi dan yang lulus seleksi kami sekolahkan ke Universiti Teknologi Malaysia (UTM) untuk program Doktoral dan Magister. Sekarang sudah ada beberpa dosen yang sudah selesai dan sudah mengajar di Sekolah Tinggi Teknologi Pelalawan (STTP)", (Wawancara : 20 April 2017)

Tabel 2. Tenaga Pengajar Sekolah Tinggi Teknologi Pelalawan (STTP)

\begin{tabular}{lll}
\hline \multicolumn{1}{c}{ No } & \multicolumn{1}{c}{ Nama } & \multicolumn{1}{c}{ Universitas } \\
\hline 1 & Prof. Dr. -Ing. Eko Supriyatno & Univ. of Federal Armed Forces \\
& & Hamburg. Jerman \\
2 & Dr. Salmiyati, M.Pd & UTM, Malaysia \\
3 & Sugoro Bhakti Sutono, S.T., M.Eng & UGM, Indonesia \\
4 & Febrianti, S.P., M.Si & IPB, Indonesia \\
5 & Dr. Fitra Lestari & UTM, Malaysia \\
6 & Reiza Mutia, S.T.P., M. Eng & UTM, Malaysia \\
7 & Widya Laila, S.T., M.T & ITB, Indonesia \\
8 & Akhmad Zulkifli, S. Kom., M.Kom & UPI, Indonesia
\end{tabular}


Pivit Septiary Chandral Implementasi Kebijakan Pembangunan Kawasan Teknopolitan dalam Bidang Pendidikan di Kabupaten Pelalawan

\begin{tabular}{lll}
9 & Salman Alfarisi, S.T., M.T & ITS, Indonesia \\
10 & Cecep Ijang Wahyudin, S.P., M.Si & UNRI, Indonesia \\
11 & Desrihastuti, S.P., M.Sc & UKM, Malaysia \\
12 & Cici Marasyid, S.t., M. Eng & UTM, Malaysia \\
13 & Asep Rodiansyah, S.P., M.Si & ITB, Indonesia \\
14 & Syofia Asridawati, S.P., M.Si & IPB, Indonesia \\
\hline \multicolumn{3}{r}{ Sumber $:$ Sekolah Tinggi Teknologi Pelalawan (STTP)(2017) }
\end{tabular}

\section{Sosialisasi dan Promosi}

Dalam Peraturan Bupati No. 32 Tahun 2015 Tentang Pembangunan dan Pengelolaan Kawasan Teknopolitan Pasal 6 bagian (b) menyebutkan bahwa Pemerintah Kabupaten Pelalawan menetapkan Kebijakan Strategi membuka peluang bagi masyarakat dan dunia usaha secara luas untuk turut serta berpartisipasi dalam pengembangan kawasan.

Berdasarkan peraturan tersebut maka perlu dilakukan sosialisasi dan promosi kepada masyarakat maupun dunia usaha agar mampu berpartisipasi dalam pengembangan kawasan Teknopolitan.

Dalam Kamus Besar Bahas Indonesia (KBBI) Sosialisasi berarti upaya memasyarakatkan sesuatu sehingga menjadi dikenal, dipahami, dihayati oleh masyarakat. Sedangkan Promosi berarti memperkenalkan dan mempropagandakan (tentang suatu usaha dan sebagainya).

Dalam sosialisasi dan promosi kawasan teknopolitan terutama Sekolah Tinggi Teknologi Pelalawan (STTP) peneliti melakukan wawancara dengan Asisten I Bagian Pemerintahan Bupati Pelalawan Drs. Zulhelmi, M.Si yang mengatakan bahwa Pemerintah Kabupaten Pelalawan terus melakukan sosialisasi dan promosi terkait kawasan Teknopolitan kepada masyarakat. Terutama Bupati Pelalawan yang terus mempromosikan Sekolah Tinggi Teknologi Pelalawan di kawasan Teknopolitan. Berikut kutipan hasil wawancara dengan Asisten I Bagian Pemerintahan Bupati Pelalawan

"Kita terus melakukan sosialisasi dan promosi kawasan Teknopolitan ke masyarakat. Setiap saat kita mengkampanyekan bahwa kawasan Teknopolitan ini adalah program yang sangat menjanjikan bagi Kabupaten Pelalawan. Kalau untuk Sekolah Tinggi Teknologi Pelalawan (STTP) Bupati kita juga terus mempromosikan disetiap kesempatan jadi pembicara. Jadi Bupati kita mengharapkan agar putra putri daerah tidak harus lagi kuliah keluar daerah karna di Pelalawan saat ini juga sudah ada sekolah tinggi" (Wawancara :20 April 2017)"

Sosialisasi dan promosi terkait Sekolah Tinggi Teknopolitan Pelalawan (STTP) di Kawasan Teknopolitan sudah dilaukukan cukup gencar oleh Pemerintah Kabupaten Pelalawan. Hal ini dapat dilihat dari peran Bupati Pelalawan yang terus melakukan sosialisasi dan promosi disetiap kegiatan kedinasan maupun kesempatan lainnya. Badan Perencanaan Pembangunan Daerah juga selalu melakukan sosialisasi dan promosi terkait Kawasan Teknopolitan di setiap kegiatan Expo yang diadakan baik di tingkat kabupaten maupun ditingkat provinsi. Sekolah Tinggi Teknologi Pelalawan (STTP) sendiri juga cukup aktif dalam melakukan sosialisasi dan promosi ke sekolah-sekolah yang ada di Kabupaten Pelalawan dan juga melalui media cetak dan baliho-baliho.

\section{Subsidi Pendidikan}

Pemerintah Kabupaten Pelalawan memberikan subsidi pendidikan bagi Sekolah Tinggi Teknologi Pelalawan (STTP) sebagai penyedia SDM bagi Kawasan Teknopolitan guna meningkatkan kualitas SDM yang dibutuhkan Kawasan Teknopolitan berbentuk Beasiswa bagi Tenaga Pengajar Sekolah Tinggi Teknologi Pelalawan (STTP) dan Beasiswa Bagi Mahasiswa Sekolah Tinggi Teknologi Pelalawan (STTP). 
Sekolah Tinggi Teknologi Pelalawan (STTP) didirikan Pemerintah Kabupaten Pelalawan telah jauh-jauh hari menyiapkan tenaga pengajar. Jadi para calon tenaga pengajar diseleksi oleh Pemerintah Kabupaten Pelalawan dan yang lulus seleksi di sekolahkan ke Malaysia untuk program Doktoral dan Magister. Disini Pemerintah Kabupaten Pelalawan bekerja sama dengan Universiti Teknologi Malaysia (UTM) untuk proses perkuliahan tenaga pengajar yang akan mengajar di Sekolah Tinggi Teknologi Pelalawan (STTP). Dan saat ini telah ada beberapa tenaga pengajar yang telah menyelesaikan studinya dan langsung mengajar di Sekolah Tinggi Teknologi Pelalawan (STTP).

Selain beasiswa pendidikan, Pemerintah Kabupaten Pelalawan juga memberikan beasiswa penelitian bagi tenaga pengajar. Ini bertujuan agar hasil penelitian yang dilakukan dapat diaplikasikan dan bermanfaat bagi perkembangan kawasan teknopolitan pelalawan.

Beasiswa yang diberikan Pemerintah Kabupaten Pelalawan kepada mahasiswa Sekolah Tinggi Teknologi Pelalawan
(STTP) dalam bentuk biaya perkuliahan sudah tersalurkan dengan baik. Selain itu beasiswa juga diberikan dalam bentuk uang catur darma, uang SKS. Jadi mahasiswa tidak perlu lagi memikirkan biaya kuliah sehingga dapat lebih focus pada pembelajaran.

\section{Partisipasi Stakeholder}

Stakeholder yang terlibat tidak hanya pihak swasta, namun juga dari pihak DinasDinas yang berkaitan dengan Kawasan Teknopolitan. Ini dapat dilihat dari peran Dinas Pekerjaan Umum yang terus menggesa pembangunan menuju area Teknopolitan dari tahun ke tahun dan penyelesaian pembangunan kampus Sekolah Tinggi Teknologi Pelalawan (STTP) di Kawasan Teknopolitan. Pihak swasta seperti RAPP juga cukup berperan aktif seperti pembangunan landscape atau taman dan Dinas Lingkungan Hidup dan Kehutanan yang juga berperan dalam pembangunan Kebunn Raya Pelalawan sehingga mahasiswa dan dosen bisa langsung praktek langsung dan melakukan penelitian.

Tabel 3. Perusahaan Yang Bekerjasama Dengan Sekolah Tinggi Teknologi Pelalawan (STTP)

\begin{tabular}{cll}
\hline No & \multicolumn{1}{c}{ Nama Perusahaan } & \multicolumn{1}{c}{ Produk Usaha } \\
\hline 1 & PT. Riau Andalan Pulp and Paper & Kertas, Bubur Kertas \\
2 & PT. Sari Lembah Subur & Minyak Kelapa Sawit \\
3 & PT. Wilmar Group & Minyak Kelapa Sawit \\
4 & PT. Surya bratasena plantation & Minyak Kelapa Sawit \\
5 & PT. Adei plantation and industry & Minyak Kelapa Sawit \\
6 & PT. Astra Agro Lestari & Minyak Kelapa Sawit \\
7 & PT. Mitra Unggul Pusaka & Latex, Karet Remah (Crum Rubber) \\
8 & PT. Multi Palma Sejahtera & Minyak Kelapa Sawit \\
9 & PT. Inti Indosawit Subur & Minyak Kelapa Sawit \\
\hline
\end{tabular}
Sumber : Sekolah Tinggi Teknologi Pelalawan (STTP)

\section{PENUTUP}

Dari hasil penelitian yang telah peneliti lakukan mengenai Implementasi Kebijakan Pembangunan Kawasan Teknopolitan di Bidang Pendidikan di Kabupaten Pelalawan maka peneliti menarik kesimpulan sebagai berikut : Kebijakan pembanguna kawasan teknopolitan Pelalawan merupakan insiatif Pemerintah
Kabupaten Pelalawan mewadahi pencapaian visi Masterplan Percepatan Perluasan Pembangunan Ekonomi Indonesia (MP3EI) 2010-2025 sekaligus merealisasikan pencapaian sasaran Rencana Pembangunan Jangka Panjang Daerah (RPJPD).

Kawasan Teknopolitan Pelalawan merupakan suatu kawasan yang terpadu 
dengan perguruan tinggi sebagai pencetak tenaga kerja terampil dan pusat riset sebagai pengembang inovasi melalui pengintegrasian komitmen dan sumber daya Pemerintah, masyarakat, pihak swasta yang terencana menyeluruh dan berkelanjutan.

Implementasi Kebijakan Pembangunana Kawasan Teknopolitan di Bidang Pendidikan di Kabupaten Pelalawan suda berjalan dengan baik sesuai dengan Peraturan Bupati Nomor 32 Tahun 2015 Tentang Pengelolaan dan Pembangunan Kawasan Teknopolitan.

Hal ini dapat dilihat dari indikator penelitian yang meneliti tiga indikator. Pertama, Pengembangan Sekolah Tinggi Teknologi Pelalawan (STTP) disini dapat peneliti simpulkan bahwa indicator ini sudah terlaksana dengan cukup baik. Hal ini dapat sarana dan prasarana yang menunjang perkuliahan yang tersedia di Sekolah Tinggi Teknologi Pelalawan (STTP) seperti ruang kelas, infokus, dan alat praktek. Namun dalam hal ini masih terdapat beberapa kekurangan kecil seperti alat praktek yang belum lengkap, namun hal ini disebebkan oleh proses pemindahan dari kampus sementara ke kampus utama yang berada di kawasan teknopolitan. Kedua, Subsidi Pendidikan yang diberikan oleh Pemerintah Kabupaten Pelalawan sudah tersalurkan dengan tepat baik untuk mahasiswa maupun tenaga pengajar. Ini dapat kita lihat dari tidak perlunya mahasiswa membayar uang perkuliahan persemester karena sudah di subsidi oleh Pemerintah Pelalawan serta Beasiswa bagi tenaga pengajar yang diberikan juga sudah tersalurkan dengan baik seperti beasiswa belajar dan beasiswa penelitian bagi kemajuan Kawasan Teknopolitan Pelalawan. Ketiga, Partisipasi Stakeholder dalam hal ini peneliti dapat melihat peran serta pihak swasta dalam mendukung pengembangan kawasan teknopolitan pelalawan cukup aktif. Peran stakeholder dalam hal ini dapat dilihat dari pelatihan dan praktek yang diberikan langsung oleh stakeholder kepada mahasiswa, sehingga mahasiswa dapat terjun langsung ke lanpangan terkait dengan bidang studi yang di tekuni oleh mahasiswa. Pelalawan (STTP) serta sarana dan prasarana pendukung lainnya. 3. Untuk Sekolah Tinggi Teknologi Pelalawan (STTP) agar dapat melaukan promosi tidak hanya di sekolah di Kabupaten Pelalawan namun juga ke Kabupaten lain sehinga peminat Sekolah Tinggi Teknologi Pelalawan (STTP) tidak hanya terpatok masyarakat Pelalawan.

\section{DAFTAR KEPUSTAKAAN}

Agustino, Leo. 2008. Dasar-Dasar Kebijakan Public. CV. ALFABETA. Bandung.

Ahmadi, Rulam. 2014. Pengantar Pendidikan : Asa dan Filasafat Pendidikan. Ar-Ruzz Media. Yogyakarta.

Arafat, Surya. Penelitian Tentang Solo Teknopark. (Program S1, Teknik Arsitektur, Universitas Muhammadiyah Surakarta).

Badan Pusat Statistik Provinsi Riau. Kabupaten Pelalawan Dalam Angka. Pekanbaru.

Gunawan, Imam. 2013. Metode Penelitian Kualitatif : Teori dan Praktik. Bumi Aksara. Jakarta.

Hakim, EM. Lukman. 2011. Pengantar Administrasi Pembangunan. Ar-Ruzz Media. Yogyakarta.

Herdiansyah, Haris. 2013. Wawancara, Observasi, dan Focus Grup Sebagai Intrumen Penggalian Data Kualitatif. PT. Raja Grafindo Persada. Jakarta.

Peraturan Bupati Nomor 32 Tahun 2013 tentang Pembangunan Kawasan Teknopolitan di Kabupaten Pelalan.

Pontoh, Nia. K, dan Iwan Kustiawan.2008. pengantar Perencanaan Perkotaan. ITB Press. Bandung. 
Pivit Septiary Chandral Implementasi Kebijakan Pembangunan Kawasan Teknopolitan dalam Bidang Pendidikan di Kabupaten Pelalawan

Siagian, P Sondang. 2010. Administrasi Pembangunan. Bumi Aksara. Jakarta.

Solichin, Abdul Wahab. 2012. Analisi Kebijakan : Dari Formulasi Ke Penyusunan Model-Model Implementasi Kebijakan Publik. Bumi Aksara. Jakarta.

UU SISDIKNAS No. 20 Tahun 2003. 